\title{
Neuroenhancing Substances Use, Exam Anxiety and Academic Performance in Bosnian-Herzegovinian First-Year University Students
}

\author{
Jasna Kusturica ${ }^{1}$, Ajša Hajdarević ${ }^{2}$, Haris Nikšić ${ }^{3}$, Amira Skopljak $^{4}$, Zana Tafi \\ Aida Kulo ${ }^{1}$
}

${ }^{1}$ Department of Pharmacology, Clinical pharmacology and Toxicology, Faculty of Medicine, University of Sarajevo, Sarajevo, Bosnia and Herzegovina, ${ }^{2}$ Medical student, Faculty of Medicine, University of Sarajevo, Sarajevo, Bosnia and Herzegovina, ${ }^{3}$ Department of Pharmacognosy, Faculty of Pharmacy, University of Sarajevo, Sarajevo, Bosnia and Herzegovina, ${ }^{4}$ Department for Family Medicine, Faculty of Medicine, University of Sarajevo, Sarajevo, Bosnia and Herzegovina, ${ }^{5}$ Institute of Occupational Medicine, Health Care Centre of Canton Sarajevo, Sarajevo, Bosnia and Herzegovina

Correspondence:

jasna.kusturica@mf.unsa.ba

Tel.: + 38761916177

Fax.: + 38733217540

Received: 18 March 2019; Accepted: 14 November 2019

\begin{abstract}
Objective. The aim of this study was to assess the relationship between the use of neuroenhancing substances, exam anxiety and academic performance among first-year Bosnian-Herzegovinian (BH) university students. Methods. In a cross-sectional study, an ad hoc questionnaire was delivered to a sample of $\mathrm{BH}$ first-year university students. The following data were collected: socio-demographic features, consumption of neuroenchancing substances, the Westside Test Anxiety Scale (WTAS) and academic performance. Results. A total of 214 students were included. Consumption of lifestyle substances, coffee, energy drinks, nicotine, alcohol, and marijuana, for the purpose of neuroenhancement increased during the week before the exams. OTC cognitive enhancer use was
\end{abstract}

reported by $31.0 \%$, and of benzodiazepines by $1.5 \%$ of students. No psycostimulants were used. A high to extremely high exam WTAS score was reported in $38.3 \%$ students. The exam WTAS score was positively correlated with consumption of coffee (rho $=0.31$; $\mathrm{P}<0.001$ ), energy drinks ( $\mathrm{rho}=0.18 ; \mathrm{P}=0.009$ ), and nicotine ( $r h o=0.22 ; \mathrm{P}=0.001$ ), and negatively correlated with last exam grade ( $r h o=-0.33 ; \mathrm{P}<0.001)$. The exam WTAS score was a significant independent predictor $(\mathrm{OR}=0.55 ; 95 \%$ CI 0.31 to $0.97, \mathrm{P}=0.039)$ for self-assessed academic performance. Self-assessed academic performance was positively correlated with last exam grade ( $r h o=0.15 ; \mathrm{P}=0.043$ ). Conclusions. Although first-year $\mathrm{BH}$ university students do not seem to use either prescription or illicit psycostimulants, the consumption of nicotine, alcohol, and marijuana is worrying. However, the consumption of these neuroenhancing substances seems not to be related to better self-assessed academic performance. Finally, exam anxiety seems to be a significant problem among $\mathrm{BH}$ first-year university students.

Key Words: Performance-Enhancing Substances - Lifestyle Drugs - Psycostimulants - Anxiety Academic Performance.

\section{Introduction}

The topic of neuroenhancement, defined as the use of the substances by healthy subjects in order to enhance their mood or cognitive function, has become increasingly popular $(1,2)$. These substances are frequently used among students in their academic en- 
vironment to improve their academic performance $(1,3)$. The most commonly used neuroenhancing substances are known as soft enhancers [i.e. lifestyle substances, such as caffeine, nicotine, alcohol, and over-thecounter pharmacy products (OTC)] (4). Unlike the use of soft enhancers, the use of psychostimulants, both prescription (e.g. methylphenidate, dexmethylphenidate, and modafinil) and illicit (e.g. amphetamines) presents a more serious threat for public health due to their potential for misuse (57). The reported prevalence of psycostimulant use for neuroenhancement among students varies between studies, probably at least partially due to the different definitions of neuroenhancement, and the ways the prevalence was reported (e.g. lifetime prevalence versus past year prevalence). Prevalence of psycostimulants use varies from 2.5\% to $55.0 \%$ in the United States (US) and Canada (7), and is at about $9.5 \%$ among UK and Irish students (8), but only $0.6 \%$ among Italian medical students (9). Regarding the use of both prescription and illicit psycostimulants, prevalances of $5.5 \%$ and $0.12 \%$ among Australian students (10), 5.8\% and $3.5 \%$ among German students $(11,12), 4.1 \%$ and $0.6 \%$ among Swiss students (4), and $2.5 \%$ and $0.6 \%$ among Dutch students (13), have been reported respectively.

Evidence of the neuroenhancement efficacy of substances used for this purpose in healthy humans, including data from randomized clinical trials, is still very limited $(5,14,15)$. Available data suggest some effects of caffeine and nicotine on attention and memory function (16-18). Regarding OTC cognitive enhancers, despite the insufficient evidence for their efficacy $(19,20)$, their popularity and international sales are rapidly growing, and exceed $\$ 1$ bn a year (21). The cognitive effects of psycostimulants (processing speed, decision-making, planning, and cognitive perseveration) have been shown to be more evident in subjects with lower baseline cognitive performance $(7,22)$.

Studies have shown that university students use neuroenhancing substances not only for cognitive enhancement, but also to cope with psychosocial stressors $(6,23)$, including exam anxiety which is reported to be a widespread but underestimated and neglected problem (24). In a survey conducted in Germany, more than $50.0 \%$ of first and second year, and $70.0 \%$ of third, fourth and fifth-year medical students stated that obvious exam anxiety had not been considered by lecturers (25). Also, a study in Iran on first-year students documented moderate exam anxiety in $40.3 \%$, and severe exam anxiety in $11.9 \%$ of students (26).

To our knowledge, no previous study has investigated this topic on Bosnian-Herzegovinian (BH) university students, and, having reviewed the literature on the topic, we hypothesized that their level of exam anxiety is high, as well as their use of cognitive enhancers. The aim of this study was to assess the relationship between use of neuroenhancing substances, exam anxiety and academic performance among $\mathrm{BH}$ first-year university students.

\section{Subjects and Methods}

\section{Study Design and Study Population}

This cross-sectional study included first-year students at the Medical Faculty and the Faculty of Economics of the University of Sarajevo, in the 2015/2016 academic year. Ethical approval was obtained from the Medical Faculty of the University of Sarajevo.

\section{Data Collection}

The students participated in an anonymous questionnaire. A written information sheet explained the purpose of the study, including the warning that only substance use 
for the purpose of cognitive enhancement was to be considered, and students had the opportunity to accept or decline any further participation with no repercussions. The questionnaire related to (1) age, gender, socioeconomic status (i.e. low, medium, high), place of residence; (2) questions related to the week before the exams, including: (2a) the exam Westside Test Anxiety Scale (WTAS); (2b) assessment of any increase in physical activity compared to an ordinary week; (2c) assessment of any increase in the consumption of coffee, energy drinks, cigarettes, alcohol and marijuana compared to an ordinary week; (2d) assessment of OTC and prescription drug use and the reasons for their use; (3) academic performance (i.e. last exam grade, self-assessment of academic performance).

As a measure of academic accomplishment, academic performance was also selfassessed based on the statement: "My academic performance is higher than other students' performance", using a 5-point scale as follows: $1=$ not at all/ never true; $2=$ slightly/ seldom true; $3=$ moderately/sometimes true; $4=$ highly/usually true; $5=$ extremely/always true. Increased consumption of lifestyle substances and marijuana was rated on the same 5-point scale.

\section{Statistical Analysis}

Data were coded and analysed using the SPSS statistical package (SPSS Inc., Chicago, IL, USA) version 17. Continuous numerical variables with normal distribution were expressed as mean \pm standard deviation, and those that were not normally distributed as median and $25^{\text {th }}$ and $75^{\text {th }}$ percentiles. $\mathrm{Nu}$ merical variables were compared using either parametric or nonparametric tests, when appropriate. Correlation between the variables was tested using the Pearson $R$ test or the Spearman Test. Stepwise binary logistic regression was used to assess how well the predictor variables (i.e. place of residence, physical activity, last exam grade, exam WTAS score, consumption of coffee, energy drinks, nicotine, alcohol, marijuana, and OTC use) predicted self-assessed academic performance. Self-assessed academic performance was converted from the 5-point scale into 2 categories: No (never true to seldom true) or Yes (moderately to always true). The multivariate logistic model included covariates that had reached a $\mathrm{p}$ value less than 0.25 level of statistical significance in the univariate analysis. In the multivariate regression analysis, $\mathrm{P}$-value less than 0.05 was set to identify association between covariables.

\section{Results}

Of the 218 first-year students available, 214 (98.2\%) responded, and 210 students answered all the questions. Their median age was $20(20-21)$ years. The students were mainly women $74.0 \%$ (158/214). Regarding socioeconomic status, $88.5 \%(186 / 210)$ students reported middle, $10.9 \%$ (23/210) low, and $0.5 \%(1 / 210)$ high status. The majority of students reported that they were living with their parents (59.6\%), 21.1\% in a rented apartment, $10.8 \%$ in their own apartment, and $8.5 \%$ in a dormitory.

Regarding changes in physical activity in the week before exams, $14 \%$ of the students reported increased physical activity to be usually or always true, $27.6 \%$ reported it to be seldom or sometimes true, and the majority (58.4\%) reported no change in physical activity.

Consumption of lifestyle substances for the purpose of neuroenhancement increased during the week before the exams (Table 1). Consumption of coffee increased in $72.9 \%(156 / 214)$, of energy drinks in $58.4 \%$ $(125 / 214)$, of nicotine in $37.8 \%(81 / 214)$, of alcohol in $24.7 \%$ (53/214), and of marijuana in $19.0 \%(40 / 211)$ students. 
Table 1. The Proportion of Students with Increased Consumption of Lifestyle Substances Coffee, Energy Drinks, Nicotine, Alcohol and Marijuana the Week before Exams, Compared to an Ordinary Week

\begin{tabular}{llllll}
\hline \multirow{2}{*}{ Student's rating } & \multicolumn{2}{l}{ Proportion of students with increased consumption } & & Nicotine \\
\cline { 2 - 6 } & $\begin{array}{l}\text { Coffee } \\
(\mathrm{N}=214)\end{array}$ & $\begin{array}{l}\text { Energy drinks } \\
(\mathrm{N}=214)\end{array}$ & $\begin{array}{l}\text { Alcohol } \\
(\mathrm{N}=21)\end{array}$ & $\begin{array}{l}\text { Marijuana } \\
(\mathrm{N}=211)\end{array}$ \\
\hline Never true (\%) & 27.1 & 41.6 & 62.1 & 75.2 & 81.0 \\
\hline Seldom true (\%) & 11.2 & 11.2 & 3.7 & 7.9 & 3.3 \\
\hline Sometimes true (\%) & 9.8 & 13.1 & 7.0 & 5.6 & 3.8 \\
\hline Usually true (\%) & 17.3 & 14.0 & 7.0 & 4.7 & 6.6 \\
\hline Always true (\%) & 34.6 & 20.1 & 20.1 & 6.5 & 5.2 \\
\hline
\end{tabular}

Table 2. Pre-Exam Anxiety Score Measured by the Westside Test Anxiety Scale

\begin{tabular}{ll}
\hline Pre-exam anxiety score & $\mathrm{N}(\%)$ of students \\
\hline $1.0-1.9$ (comfortably low test anxiety) & $18(8.29)$ \\
\hline $2.0-2.5$ (normal or average test anxiety) & $24(11.0)$ \\
\hline $2.5-2.9$ (high normal test anxiety) & $35(16.1)$ \\
\hline $3.0-3.4$ (moderately high) & $57(26.3)$ \\
\hline $3.5-3.9$ (high test anxiety) & $51(23.5)$ \\
\hline $4.0-5.0$ (extremely high anxiety) & $32(14.7)$ \\
\hline
\end{tabular}

OTC cognitive enhancer use was reported by $31.0 \%$ of the students. The main reasons for their use were to calm down (herbal sedatives) and to improve concentration (ginkgo biloba, royal jelly, vitamins, green tea). Of prescription drugs, only benzodiazepines were used, by $1.5 \%$ of students. No prescription or illicit psycostimulant use was reported.

The average WTAS score was $3.17 \pm 0.78$, and it was significantly higher in women compared to men ( $3.24 \pm 0.76$ vs. $2.99 \pm 0.82$; $\mathrm{P}=0.037$ ), and among economics students compared to medical students $(3.45 \pm 0.84$ vs. $2.96 \pm 0.63 ; \mathrm{P}<0.001)$. A high (3.5-3.9) to extremely high (4.0-4.5) exam WTAS score was found in $38.3 \%$ of the students (Table 2).

Positive correlations were found between the exam WTAS score and the consumption of most lifestyle substances, i.e. coffee (rho=0.31; $\mathrm{P}<0.001$ ), energy drinks ( $\mathrm{rho}=0.18 ; \mathrm{P}=0.009$ ), and nicotine ( $\mathrm{rho}=0.25$; $\mathrm{P}=0.001$ ), while the WTAS score had no correlation with the consumption of alcohol (rho=0.12; $\mathrm{P}=0.074)$, marijuana $(\mathrm{rho}=0.07$; $\mathrm{P}=0.288)$ or $\mathrm{OTC}$ drugs (rho $=0.13 ; \mathrm{P}=0.059)$.

Regarding academic performance, the average last exam grade was $8.16 \pm 1.48$, and it was higher among medical students compared to economic students $[9(8 ; 10)$ vs. $7(6 ; 8) ; \mathrm{p}<0.001]$. Regarding self-assessed academic performance, the majority of students (53.7\%) reported that it is sometimes true that their academic performance is higher compared to other students' performance. This was never true in $3.0 \%$, seldom true in $9.0 \%$, usually true in $26.9 \%$, and always true in $7.5 \%$ students.

A positive correlation was noted between the last exam grade and self-assessed academic performance ( $\mathrm{rho}=0.15 ; \mathrm{P}=0.043$ ), while the exam WTAS score was negatively correlated with the last exam grade (rho=0.33 ; $\mathrm{P}<0.001$ ).

Also, binary logistic regression analysis identified two independent predictors of selfassessed academic performance: the exam WTAS score as a negatively associated pre- 
Table 3. The Logistic Regression Model Assessing Independent Predictors of Self-Assessed Academic Performance

\begin{tabular}{|c|c|c|c|c|c|c|c|}
\hline \multirow{2}{*}{ Variables } & \multirow{2}{*}{ B } & \multirow{2}{*}{ SE } & \multirow{2}{*}{ Wald } & \multirow{2}{*}{$P$} & \multirow{2}{*}{$\operatorname{Exp}(B)$} & \multicolumn{2}{|c|}{ 95\% Cl for EXP(B) } \\
\hline & & & & & & Lower & Upper \\
\hline Living with parents & 1.462 & 0.732 & 3.991 & 0.046 & 4.315 & 1.028 & 18.109 \\
\hline Living in a dormitory & 0.789 & 0.758 & 1.084 & 0.298 & 2.201 & 0.498 & 9.717 \\
\hline Living in a rented apartment & 1.006 & 0.885 & 1.293 & 0.256 & 2.735 & 0.483 & 15.488 \\
\hline Living in own apartment & - & - & 5.016 & 0.171 & - & - & - \\
\hline Physical activity & 0.241 & 0.170 & 2.015 & 0.156 & 1.272 & 0.912 & 1.775 \\
\hline Last exam grade & 0.261 & 0.153 & 2.893 & 0.089 & 1.298 & 0.961 & 1.754 \\
\hline WTAS score & -0.598 & 0.289 & 4.270 & 0.039 & 0.550 & 0.312 & 0.970 \\
\hline Coffee consumption & 0.0025 & 0.133 & 0.035 & 0.852 & 1.025 & 0.790 & 1.330 \\
\hline Energy drinks consumption & 0.185 & 0.138 & 1.801 & 0.180 & 1.203 & 0.918 & 1.577 \\
\hline Nicotine consumption & -0.038 & 0.132 & 0.083 & 0.773 & 0.963 & 0.744 & 1.246 \\
\hline Alcohol consumption & -0.125 & 0.261 & 0.228 & 0.633 & 0.883 & 0.530 & 1.472 \\
\hline Marijuana consumption & -0.458 & 0.301 & 2.320 & 0.128 & 0.633 & 0.351 & 1.140 \\
\hline OTC use & -0.038 & 0.192 & 0.039 & 0.844 & 0.963 & 0.660 & 1.404 \\
\hline Constant & -3.442 & 2.142 & 2.583 & -108 & 0.032 & - & - \\
\hline
\end{tabular}

WTAS=Westside Test Anxiety Scale; OTC=Over the Counter; $B=$ Coefficient; $S E=S$ tandard error of the coefficient; Exp(B)=Odds ratio; $\mathrm{Cl}=$ Confidence interval; Model justification: Omnibus Tests of Model Coefficients $X^{2}(4)=243.69, p<0.0005$; Hosmer and Lemeshow Test $X^{2}=0.000$, $P=1.000 ;$ Cox \& Snell $R^{2}=0.160 ;$ Nagelkerke $R^{2}=0.221$.

dictor $[\mathrm{B}(\mathrm{SE})=-0.60(0.29)$, Wald $(1)=4.27$, $\mathrm{OR}=0.55 ; 95 \% \mathrm{CI} 0.31$ to $0.97, \mathrm{P}=0.039$ ], and living with parents as a positively associated predictor $[\mathrm{B}(\mathrm{SE})=0.46(0.73)$, Wald $(1)=3.99$, $\mathrm{OR}=4.32$; $95 \%$ CI 1.03 to $18.11, \mathrm{P}=0.046]$. Other variables tested (i.e. living in a rented apartment, living in own apartment, living in a dormitory, physical activity, last exam grade, coffee, energy drinks, nicotine, alcohol and marijuana consumption, OTC use) were shown not to predict self-assessed academic performance (Table 3 ).

\section{Discussion}

Fortunately, no students from our sample of $\mathrm{BH}$ first-year university students used psycostimulants, either prescription or illicit, for neuroenhancement purpose. The students, however, used prescription benzodiazepines, some OTC drugs and, more frequently, lifestyle substances.

Although caffeine is also the first choice for neuroenhancement in other countries, the prevalence of its use in our country seems to be higher. The traditional widespread consumption of coffee in our country may explain this finding.

The average pre-exam anxiety level in our study was moderately high (WTAS score of $3.17 \pm 0.78)$. However, high (23.5\%) to extremely high (14.7\%) levels were found with "alarming frequency". Similarly, in a study by Pighi et al. (2018) almost a third of the Italian medical students found studying stressful (9). The gender implications found in our study have also been seen in several previous studies (27-30), and the authors explained that this was due to the differences in the social roles assigned to men and women, as well as due to the increased emotional vulnerability of women $(23,29)$. Furthermore, in our study, economic students, compared to medical students, had a lower last exam grade and a significantly higher WTAS score.

In our study, anxiety was positively correlated with the consumption of caffeine and 
nicotine. In line with this, Italian medical students who worried about academic performance where more prone to use cognitive enhancers (9). However, more research is needed to explore whether anxiety makes students take more of these substances for relaxation and sedation, or whether anxiety is a side effect of their consumption. Increased exam anxiety was also associated with a lower last exam grade and, in addition, with lower self-assessed academic performance. On the other hand, living with parents was shown to be an independent predictor, significantly positively associated with self-assessed academic performance.

Although alcohol and marijuana are rarely used for the purpose of neuroenhancement (4) [e.g. $5.1 \%$ and $1.8 \%$ prevalence rates among Swiss students (4), and $3.8 \%$ and $1.0 \%$ among Australian students (10), respectively], in our study a high increase in alcohol $(24.8 \%)$ and marijuana (19.0\%) consumption during the week before an exam was found. Neither alcohol nor marijuana consumption was correlated with exam anxiety, which was also found in a study of German medical students (25). The high increase in alcohol and marijuana consumption in our study may be explained by the fact that we evaluated first-year university students, who may still tend to experiment with substance use, or have limited knowledge of the side effects of alcohol and marijuana, or have a low level of responsibility towards education.

In our study, OTC cognitive enhancers, specifically ginkgo biloba, royal jelly, magnesium, green tea, vitamin tablets, herbal sedatives, or analgesics, were used in $31.0 \%$ of students, similarly to $28.1 \%$ of Swiss university students (gingko biloba, zinc, vitamin tablets, herbal sedatives), but more than $9.5 \%$ of Dutch university students, where the specific OTC drugs used were not reported $(4,13)$. Of prescription drugs, only benzodiazepines were used in $1.3 \%$ stu- dents, similar to the $1.1 \%$ past-year prevalence among Australian students, and lower than the $2.1 \%$ prevalence reported among Swiss students $(4,13)$.

None of our students reported the use of prescription or illicit psycostimulants compared to the prevalence in other countries mentioned earlier $(4,8,10-13,31)$. Although these comparisons should be considered with caution because our study included only first-year students, the study of medical students in the US also showed psychostimulant non-users to be more likely to be first year students or to grow up outside of the US (32). Also, the reason for the unpopularity of prescription psycostimulants among BH first year university students may be their unavailability, as those drugs are not approved in BH. In the US and Canada, student psychostimulant users reported obtaining those drugs from a peer with a prescription (31), while in the UK and Ireland, two-thirds of student non-users stated that the lack of access was the only reason why they had not tried such drugs (8).

Although better academic success is assumed to be the main reason for the use of neuroenhancing substances, the literature data have reported no long-term academic benefits from them (2). This is in line with our results, where the consumption of nicotine, alcohol, marijuana and OTC cognitive enhancers seemed not to be related to better self-assessed academic performance.

\section{Limitations of the Study}

This study had several limitations: the crosssectional study design largely based on an ad hoc questionnaire; self-reported data and the lack of objective parameters of cognitive enhancers' benefits for academic results. Also, the study population included only first-year students from only two faculties of one city, and consequently the results cannot represent the whole population of first- 
year university students in BH. In addition, the regression analysis performed, dychotomizing the outcome variable, may have reduced the information originally contained in the questionnaire. However, despite the small sample size, our results indicated a significantly high level of exam anxiety among first-year medicine and economics students, suggesting the need for larger studies to confirm those findings and to inform interventional strategies, both for promotion of healthy ways of coping with stress, and for reducing consumption of neuroenhancing substances with addiction potential, i.e. nicotine, alcohol, marijuana, benzodiazepines.

\section{Conclusion}

Although the $\mathrm{BH}$ first-year university students seemed not to use either prescription or illicit psycostimulants, the consumption of nicotine, alcohol, and marijuana is worrying. However, the consumption of these neuroenhancing substances seems not to be related to better self-assessed academic performance. Finally, exam anxiety seems to be a significant problem among $\mathrm{BH}$ first-year university students, with a higher level of exam anxiety most frequently seen among students with a greater increase in coffee, energy drink, and nicotine consumption, as well as among students with lower last exam grades and lower self-assessed academic performance.

\section{What Is Already Known on this Topic:}

Neuroenhancing substances are frequently used among students in the academic environment. In general, the neuroenchancing use of prescription drugs and illicit substances is considered more problematic than the use of lifestyle substances and over-the-counter drugs. Evidence of long-term academic benefits from neuroenhancing substances use is lacking, while exam anxiety is considered one of the most important factors that affect academic achievement.

What this Study Adds:

Lifestyle substances are the most common choice for neuroenhancement prior to exams among BH first-year university students. Compared to other countries, we highlight the par- ticularly frequent increase in nicotine, alcohol and marijuana consumption, while the use of prescription and illicit psycostimulants was not reported. While a high percentage of students struggle with exam anxiety, which was shown to be an independent predictor of lower academic performance, none of the substances used was shown to contribute to better academic performance.

Authors' Contributions: Conception and design: JK, $\mathrm{AK}$ and $\mathrm{AH}$; Acquisition, analysis and interpretation of data: JK, AK and AH; Drafting the article: JK and AK; Revising it critically for important intellectual content: HN, AS and ZT; Approved final version of the manuscript: JK, AK and AS.

Conflict of Interest: The authors declare that the have no conflict of interest.

\section{References}

1. Schuijer JW, de Jong IM, Kupper F, van Atteveldt NM. Transcranial electrical stimulation to enhance cognitive performance of healthy minors: A complex governance challeng. Front Hum Neurosci. 2017;11:142.

2. Fond G, Micoulaud-Franchi JA, Macgregor A, Richieri R, Miot S, Lopez R, et al. Neuroenhancement in healthy adults, part I: Pharmaceutical cognitive cnhancement: A systematic review. J Clinic Res Bioeth. 2015;6:213.

3. Maier LJ, Schaub MP. The use of prescription drugs and drugs of abuse for neuroenhancement in Europe. Eur Psychol. 2015;20:155-66.

4. Maier LJ, Liechti ME, Herzig F, Schaub MP. To dope or not to dope: neuroenhancement with prescription drugs and drugs of abuse among Swiss university students. PLoS One. 2013; 8(11):e77967.

5. Weyandt LL, Oster DR, Marraccini ME, Gudmundsdottir BG, Munro BA, Rathkey ES, et al. Prescription stimulant medication misuse: Where are we and where do we go from here? Exp Clin Psychopharmacol. 2016;24(5):400-14.

6. Jensen C, Forlini C, Partridge R, Hall W. Australian university students' coping strategies and use of pharmaceutical stimulants as cognitive enhancers. Front Psychol. 2016;7:277.

7. Marraccini ME, Weyandt LL, Rossi JS, Gudmundsdottir BG. Neurocognitive enhancement or impairment? A systematic meta-analysis of prescription stimulant effects on processing speed, decision-making, planning, and cognitive perseveration. Exp Clin Psychopharmacol. 2016;24(4):269-84. 
8. Singh I, Bard I, Jackson J. Robust resilience and substantial interest: a survey of pharmacological cognitive enhancement among university students in the UK and Ireland. PLoS One. 2014;9:e105969.

9. Pighi M, Pontoni G, Sinisi A, Ferreri S, Mattei G, Pingani L, et al. Use and Propensity to Use Substances as Cognitive Enhancers in Italian Medical Students. Brain Sci. 2018;8(11):pii:E197.

10. Riddell C, Jensen C, Carter O. Cognitive enhancement and coping in an Australian university student sample. J Cogn Enhanc. 2018;2:63-9.

11. Wolff W, Brand R, Baumgarten F, Lösel J, Ziegler M. Modeling students' instrumental (mis-) use of substances to enhance cognitive performance: Neuroenhancement in the light of job demandsresources theory. Biopsychosoc Med. 2014;8:12.

12. Franke AG, Christmann M, Bonertz C, Fellgiebel A, Huss M, Lieb K. Use of coffee, caffeinated drinks and caffeine tablets for cognitive enhancement in pupils and students in Germany. Pharmacopsychiatry. 2011;44(7):331-8.

13. Schelle KJ, Olthof BM, Reintjes W, Bundt C, Gusman-Vermeer J, van Mil AC. A survey of substance use for cognitive enhancement by university students in the Netherlands. Front Syst Neurosci. 2015;9:10.

14. Hawkes N. Modafinil does enhance cognition, review finds. BMJ. 2015;351:h4573.

15. Kennedy DO, Jackson PA, Haskell CF, Scholey AB. Modulation of cognitive performance following single doses of $120 \mathrm{mg}$ Ginkgo biloba extract administered to healthy young volunteers. Hum Psychopharmacol. 2007;22(8):559-66.

16. Mednick SC, Cai DJ, Kanady J, Drummond SP. Comparing the benefits of caffeine, naps and placebo on verbal, motor and perceptual memory. Behav Brain Res. 2008; 3;193(1):79-86.

17. Adan A, Serra-Grabulosa JM. Effects of caffeine and glucose, alone and combined, on cognitive performance. Hum Psychopharmacol. 2010;25(4):310-7.

18. Heishman SJ, Kleykamp BA, Singleton EG. Metaanalysis of the acute effects of nicotine and smoking on human performance. Psychopharmacology (Berl). 2010;210(4):453-69.

19. Canter PH, Ernst E. Ginkgo biloba is not a smart drug: an updated systematic review of randomised clinical trials testing the nootropic effects of G. biloba extracts in healthy people. Hum Psychopharmacol. 2007;22(5):265-78.

20. Morita H, Ikeda T, Kajita K, Fujioka K, Mori I, Okada $\mathrm{H}$, et al. Effect of royal jelly ingestion for six months on healthy volunteers. Nutr J. 2012;11:77.
21. Chinthapalli K. The billion dollar business of being smart. BMJ 2015;351:h4829.

22. Kraus LJ. Increasing Awareness of Nootropic Use. Report of the council on science and public health 9-A-16. [cited 2019 February 5]. Available from: https://www.ama-assn.org/sites/ama-assn. org/files/corp/media-browser/public/about-ama/ councils/Council\%20Reports/council-on-science-public-health/a16-csaph9.pdf.

23. Pohl S, Boelsen H, Hildt E. Moral attitudes toward pharmacological cognitive enhancement (PCE): Differences and similarities among Germans with and without PCE experience. Front Pharmacol. 2018;9:1451.

24. Neuderth S, Jabs B, Schmidtke A. Strategies for reducing test anxiety and optimizing exam preparation in German university students: A preventionoriented pilot project of the University of Würzburg. J Neural Transm. 2009;116(6):785-90.

25. Tektaş OY, Paulsen F, Sel S. Test anxiety among German medical students and its impact on lifestyle and substance abuse. Med Teach. 2013;35(11):969.

26. Miri HR, Piroozan A, Hesam AA, Naderi N, Rezaei P. Determining the level of test anxiety and some of its contributing factors among the freshmen students. Life Sci J. 2013;10(9s):149-55.

27. Latas M, Pantic M, Obradovic D. Analysis of test anxiety in medical students. Med Pregl. 2010;63(11-12):863-6.

28. Nourse R, Adamshick P, Stoltzfus J. College binge drinking and its association with depression and anxiety: A prospective observational study. East Asian Arch Psychiatry. 2017;27(1):18-25.

29. Javadi M, Jourabchi Z, Shafikhani AA, Tajik E. Prevalence of depression and anxiety and their association with body mass index among high school students in Qazvin, Iran, 2013-2014. Electron Physician. 2017;9(6):4655-60.

30. Afzal H, Afzal S, Siddique SA, Naqvi SA. Measures used by medical students to reduce test anxiety. J Pak Med Assoc. 2012;62(9):982-6.

31. Smith ME, Farah MJ. Are prescription stimulants "smart pills"? The epidemiology and cognitive neuroscience of prescription stimulant use by normal healthy individuals. Psychol Bull. 2011;137(5):717-41.

32. Emanuel RM, Frellsen S, KashimaK, Sanguino S, Sierles FS, Lazarus CJ. Cognitive Enhancement Among Medical Students Cognitive-Enhancement Drug Use Among Future Physicians: Findings From A Multi Institutional Census of Medical Students. J Gen Intern Med. 2013;28(8):1028-34. 